International Journal on Cybernetics \& Informatics ( IJCI) Vol.2, No.1, February 2013

\title{
DESIGN OF A LINEAR AND WIDE RANGE CURRENT STARVEd VOLTAGE CONTROLlEd OSCILlator FOR PLL
}

\author{
Mr. Madhusudan Kulkarni ${ }^{1}$ and Mr. Kalmeshwar N Hosur ${ }^{2}$ \\ ${ }^{1}$ M.Tech student \\ ${ }^{2}$ Asst. Professor (Senior Grade) \\ Department of Electronics and Communication Engineering \\ SDM College of Engineering and Technology, Dharwad, Karnataka, INDIA \\ ${ }^{1}$ madhusudankulkarni15@gmail.com, ${ }^{2}$ kalmeshwar10@rediffmail.com
}

\begin{abstract}
This paper focuses on design and analysis of Current Starved Ring Voltage Controlled Oscillators (CSVCO) for PLL application. The CSVCO circuit is designed and simulated using GPDK 180nm CMOS Technology. The CSVCO has frequency range from $53 \mathrm{MHz}$ to $2.348 \mathrm{GHz}$ and power consumption is $848 \mu W$. The jitter is improved by connecting a D Flip Flop. In this design the maximum time jitter after D flip flop is 3.1ps and 1.5ps for rising and falling edge respectively and output frequency is from $173 \mathrm{MHz}$ to $1.2 \mathrm{GHz}$. The supply voltage $V_{D D}$ is $1.8 \mathrm{~V}$.
\end{abstract}

\section{KEYWORDS}

Ring Oscillator, Voltage Controlled Oscillator (VCO), Current Starved Voltage Controlled Oscillator (CSVCO).

\section{INTRODUCTION}

In VLSI field the design of a linear and wide range voltage controlled oscillator for RF application is a challenging work for Electronics Engineers. VCO is the main component in the many RF circuits. VCO is the heart of Phase Lock Loop system. An oscillator is an autonomous system which generates a periodic output without any input. The VCO is an electronic circuit which produces the frequency signal depending on its input voltage. VCO is voltage to frequency converter. The Barkhausen criteria for oscillation can be met without resonators as in ring oscillators. If the open loop circuit exhibits sufficient gain at the zero phase frequency, oscillations occurs. The important requirements of VCO are Frequency accuracy, wide tuning range, tuning linearity, low power consumption, small size and low phase noise [1].

\section{DIFFERENT ARCHITECTURES OF VCO}

The different architectures of VCO are

\subsection{LC VCO}

These VCO's are made by using inductors and capacitors, with an amplifier. A very high frequency voltage controlled oscillations are generated by using inductors and capacitors. This architecture is preferred for sinusoidal wave output and can be integrated where space is not important issue. 


\subsection{Source Coupled VCO}

These VCOs are made by using transistors connected back to back. This technique gives high frequency VCOs. These are also used to generate rectangular and saw tooth wave forms. These VCOs can be designed to dissipate less power than the current-starved VCO. The major disadvantage of these configurations is the need for a capacitor, something that may not be available in a single-poly pure digital process without using parasitic.

\subsection{Current Starved Ring VCO}

These VCOs are made by using ring oscillator. The ring oscillator works by controlling the charging and discharging of the gate capacitance of the next inverter. Decreasing the peak available charging current increases the time to charge and discharge the gate capacitance; consequently, the frequency is decreased [7]. Ring oscillators generate high frequency up to 10 $\mathrm{GHz}$.

\section{TRANSFER FunCtion OF VCO}

Ideally the VCO must be capable of transfer the input voltage to frequency linearly as shown in Figure 1.

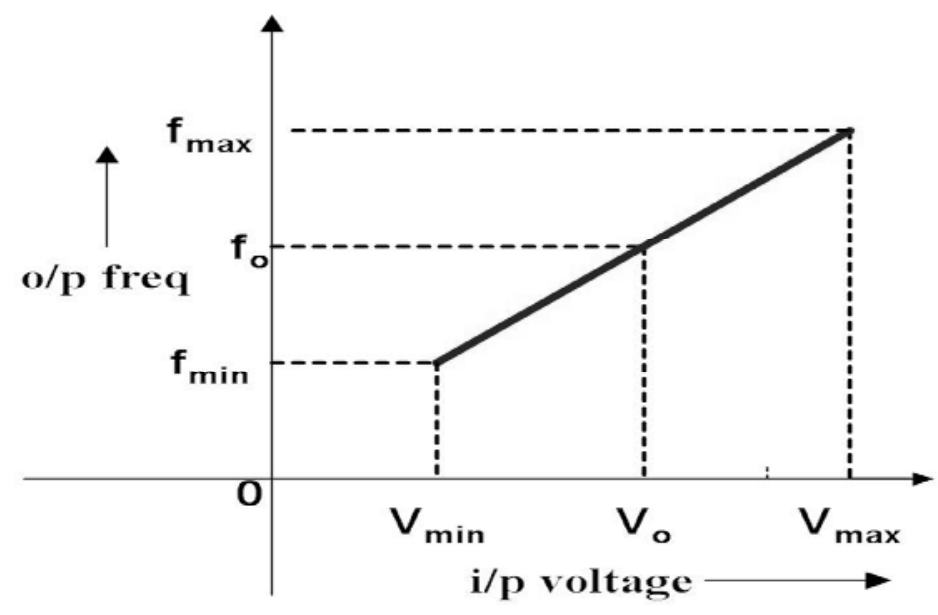

Figure 1. Transfer Function of VCO

The output frequency of the VCO is given by

where

$$
\omega_{\text {out }}=\omega_{0}+K_{V C O} \cdot V_{\text {invco }} \mathrm{rad} / \mathrm{sec}
$$

$\mathrm{V}_{\text {invco }}$ is the input voltage to the $\mathrm{VCO}$,

$\omega_{\mathrm{o}}$ is the free running frequency,

$\mathrm{K}_{\mathrm{VCO}}$ is the gain of the $\mathrm{VCO}$ and is given by

$$
K_{V C O}=2 \pi \cdot \frac{f_{\max }-f_{\min }}{V_{\max }-V_{\min }} \mathrm{rad} / \mathrm{sec}-\text { volts }
$$

\section{VCO DESIGN \\ 4.1. VCO Design parameters}

The VCO designed according to the following specifications as shown in Table 1. 
International Journal on Cybernetics \& Informatics ( IJCI) Vol.2, No.1, February 2013

Table 1. VCO Design Specifications

\begin{tabular}{|l|l|}
\hline Parameter & Value \\
\hline Power supply $\left(\mathrm{V}_{\mathrm{DD}}\right)$ & $1.8 \mathrm{~V}$ \\
\hline Centre frequency & $1 \mathrm{GHz}$ \\
\hline No of inverter stages & 3 \\
\hline Inverter delay & $35 \mathrm{ps}$ \\
\hline Random jitter $(\mathrm{rms})$ & $<20 \mathrm{ps}$ \\
\hline Technology & GPDK $180 \mathrm{~nm}$ \\
\hline
\end{tabular}

\subsection{Ring oscillator}

The ring oscillator is made up of 3 inverters connected in ring fashion as shown in Figure 2. The length is fixed at $180 \mathrm{~nm}$. The width of PMOS transistor is $3 \mathrm{~m}$ and width of NMOS is $700 \mathrm{~nm}$ is considered for switching point $\left(\mathrm{V}_{\mathrm{SP}}\right)$ at $0.9 \mathrm{~V}$. The average delay of each inverter with an inverter as load is $35 \mathrm{ps}$.

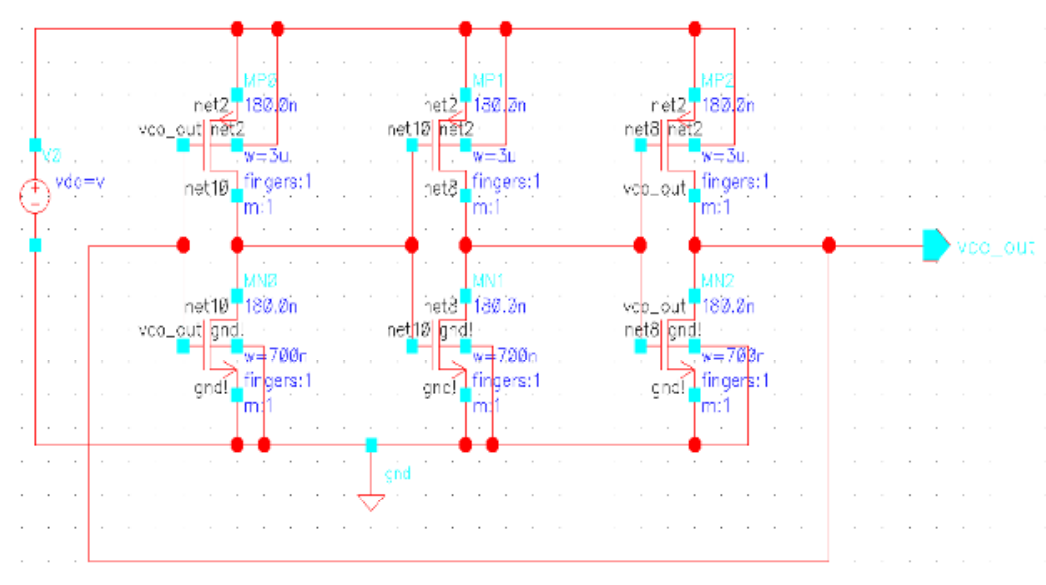

Figure 2. Schematic of Ring Oscillator.

The frequency of this ring oscillator will be

$$
f_{\text {osc }}=\frac{1}{2 . N . T_{d}} \mathrm{~Hz}
$$

where

$\mathrm{N}$ is number of inverter stages $=3$

$\mathrm{T}_{\mathrm{d}}$ is the average time delay of each inverter $=35 \mathrm{ps}$

Oscillation frequency is $4.698 \mathrm{GHz}$.

\subsection{Why current starved architecture?}

The $\mathrm{V}_{\mathrm{DD}}$ varies $\pm 10 \%$ of $1.8 \mathrm{~V}$ i.e. from $1.62 \mathrm{~V}$ to $1.98 \mathrm{~V}$. For this voltage variation the Ring architecture produces an output frequency from $4.175 \mathrm{GHz}$ to $5.077 \mathrm{GHz}$ with the difference of $992 \mathrm{MHz}$, which is large variation as shown in Figure 3. 

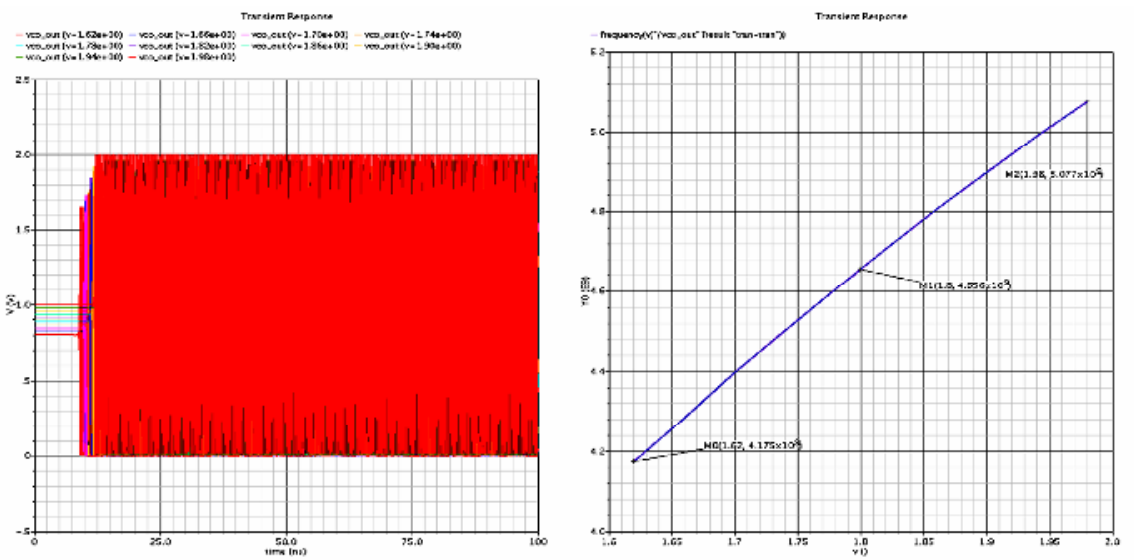

Figure 3. Vdd versus output frequency of ring VCO.

The output frequency is not stable when it is dependent on $\mathrm{V}_{\mathrm{DD}}$. This is made stable by supplying current to each inverter instead of $\mathrm{V}_{\mathrm{DD}}$ as shown in Figure 4.

\subsection{Current Starved VCO}

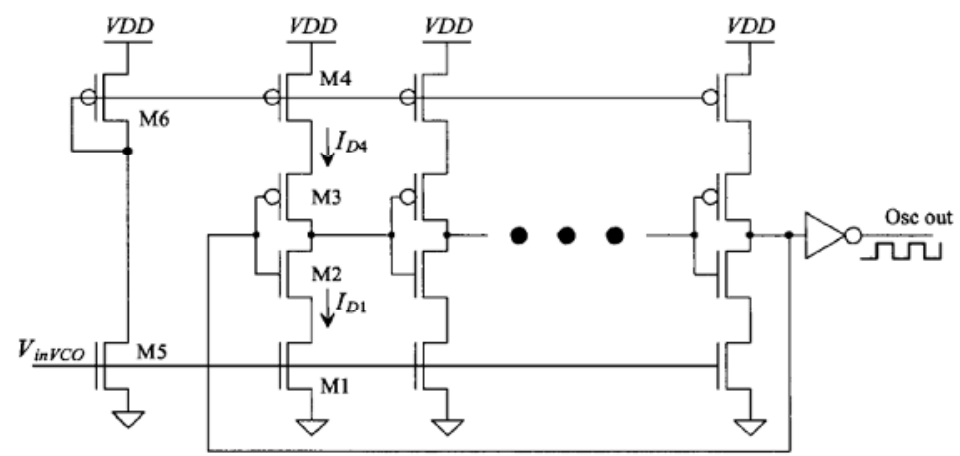

Figure 4. Schematic of Current Starved VCO [2]

The schematic of current-starved VCO is shown in Figure4. Its operation is similar to the ring oscillator. MOSFETs M2 and M3 operate as an inverter, while MOSFETs M1 and M4 operate as current sources. The current sources, M1 and M4, limit the current available to the transistor M2 and M3. In other words, the inverter is starved for current. The drain currents of MOSFETs M5 and M6 are the same and are set by the input control voltage. The currents in M5 and M6 are mirrored in each inverter/current source stage.

The total capacitance on the drains of M2 and M3 is given by

$$
\begin{aligned}
& C_{\text {tot }}=C_{\text {out }}+C_{\text {in }} \\
& C_{\text {tot }}=C_{\text {ox }}^{\prime}\left(W_{p} L_{p}+W_{n} L_{n}\right)+\frac{3}{2} C_{\text {ox }}^{\prime}\left(W_{p} L_{p}+W_{n} L_{n}\right)
\end{aligned}
$$

This is simply the output and input capacitances of the inverter. This equation can be written in a more useful form as

$$
C_{\text {tot }}=\frac{5}{2} C_{o x}^{\prime}\left(W_{p} L_{p}+W_{n} L_{n}\right)
$$

The time taken to charge $C_{\text {tot }}$ from zero to $V_{S P}$ with the constant current $I_{D 4}$ is given by

$$
t_{1}=C_{t o t} \cdot \frac{V_{S P}}{I_{D 4}}
$$

where $\mathrm{V}_{\mathrm{SP}}$ is switching point of the inverter.

While the time taken to discharge $C_{\text {tot }}$ from $V_{D D}$ to $V_{S P}$ is given by 
International Journal on Cybernetics \& Informatics ( IJCI) Vol.2, No.1, February 2013

$$
t_{2}=C_{t o t} \cdot \frac{V_{D D}-V_{S P}}{I_{D 1}}
$$

If we set $I_{D 4}=I_{D 1}=I_{D}$ (which we will label $I_{D c e n t r e}$ when $V_{\text {inVCO }}=V d d / 2$ ), then the sum of $t_{1}$ and $t_{2}$ is simply

$$
t_{1}+t_{2}=\frac{C_{t o t} \cdot V_{D D}}{I_{D}}
$$

The oscillation frequency of the current-starved VCO for $\mathrm{N}$ (an odd number $>3$ ) stages is

$$
f_{\text {osc }}=\frac{1}{N\left(t_{1}+t_{2}\right)}=\frac{I_{D}}{N \cdot C_{t o t} \cdot V_{D D}}
$$

which is equal to $\mathrm{f}_{\text {center }}\left(\right.$ at $\mathrm{V}_{\text {inVCO }}=\mathrm{V}_{\mathrm{DD}} / 2$ and $\mathrm{I}_{\mathrm{D}}=\mathrm{I}_{\text {Dcenter }}$ ). The VCO stops oscillating, when $\mathrm{V}_{\text {inVCO }}<\mathrm{V}_{\mathrm{TN}}$. Therefore, we can define $\mathrm{V}_{\min }=\mathrm{V}_{\mathrm{TN}}$ and $\mathrm{f}_{\min }=0$. The maximum $\mathrm{VCO}$ oscillation frequency, $f_{\max }$ is determined by finding $I_{D}$ when $V_{\text {inVCO }}=V_{D D}$. At the maximum frequency, $\mathrm{V}_{\max }=\mathrm{V}_{\mathrm{DD}}$.

\subsection{Linearizing VCO Gain}

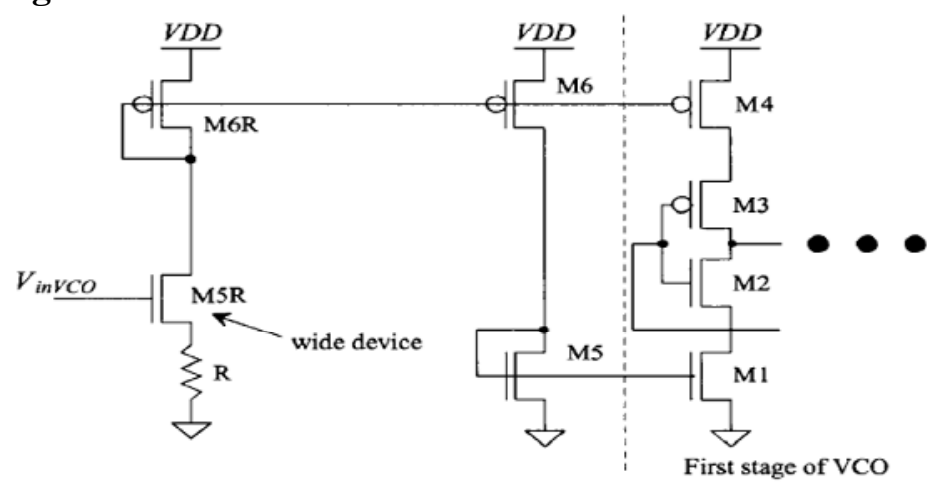

Figure 5. Linearizing VCO Gain [2]

To make the current in a MOSFET linearly related to the VCO's input voltage, consider the circuit shown in Figure 5. The width of M5R is made wide so that its $V_{G S}$ is always approximately $\mathrm{V}_{\mathrm{TN}}$. Note that the current in M6R is mirrored over to M6 and M5 to control the current used in the current-starved VCO.

The drain current of M5R is shown in Figure 6. The drain current linearity is also depends on the width of M6R transistor. The width of M6R is $10 \mu \mathrm{m}$ and the width of M5R is made high and is taken as $100 \mu \mathrm{m}$. The Figure 6 shows the $V_{\text {invco }}$ vs drain current of M5R transistor. Drain current is linearly dependent on $\mathrm{V}_{\text {invco. }}$.

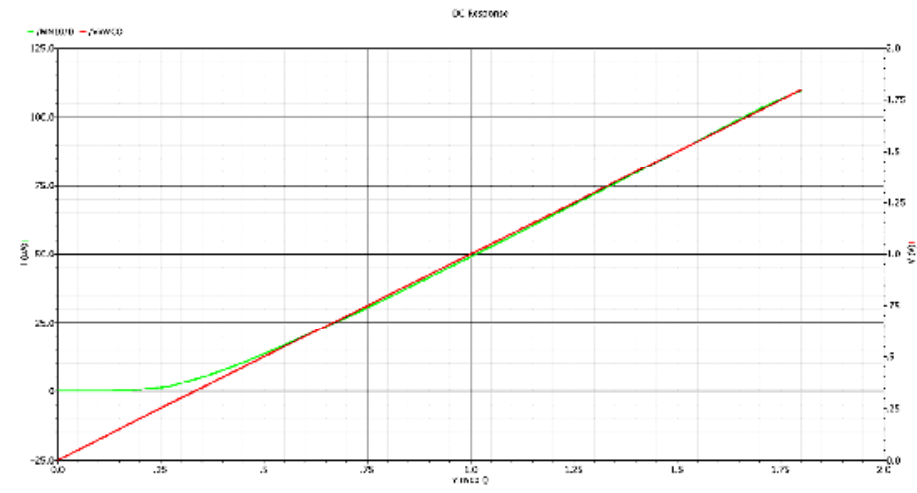

Figure 6. Drain current of M5R versus $\mathrm{V}_{\text {invco. }}$.

The average current drawn by the VCO is 
International Journal on Cybernetics \& Informatics ( IJCI) Vol.2, No.1, February 2013

or

$$
\begin{aligned}
& I_{\text {avg }}=N \cdot \frac{V_{D D} C_{t o t}}{T}=N \cdot V_{D D} \cdot C_{t o t} \cdot f_{o s c} \\
& \mathrm{I}_{\mathrm{avg}}=\mathrm{I}_{\mathrm{D}}
\end{aligned}
$$

The average power dissipated by the VCO is

$$
P_{a v g}=V_{D D} \cdot I_{a v g}=V_{D D} \cdot I_{D}
$$

\section{IMPLEMENTATION AND RESULTS}

The final design of linear wide range current starved voltage controlled oscillator is shown in Figure 7.

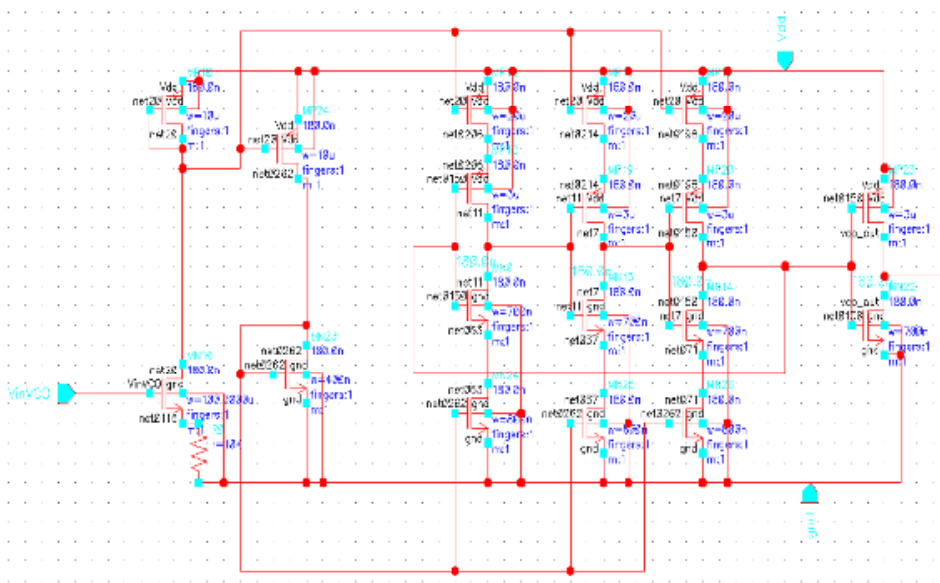

Figure 7. Complete Current Starved VCO

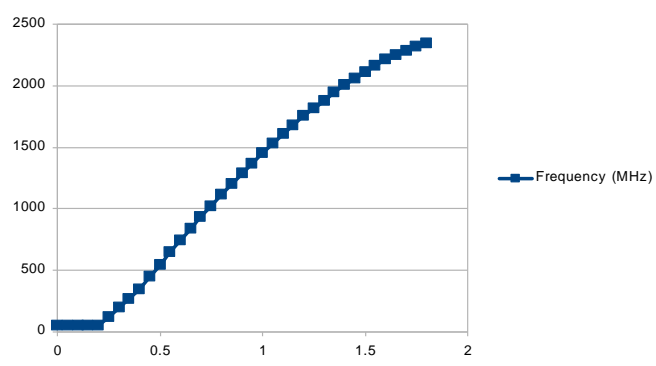

Figure 8. Vinvco versus output frequency

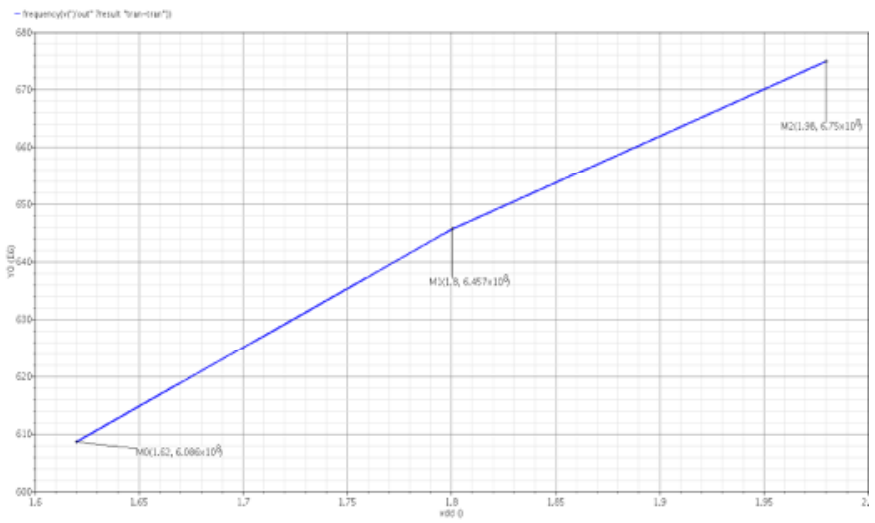

Figure 9. Vdd versus output frequency of current starved VCO in cadence, difference is $64 \mathrm{MHz}$. 
It is observed from Figure 9 that the variation in $\mathrm{V}_{\mathrm{DD}}$ from $1.62 \mathrm{~V}$ to $1.98 \mathrm{~V}$ i.e. $\pm 10 \%$ of $1.8 \mathrm{~V}$, which varies the output frequency by $64 \mathrm{MHz}$. Therefore the output frequency of VCO is controlled by current. This produces stable oscillations irrespective of $\mathrm{V}_{\mathrm{DD}}$ variations.

\subsection{Jitter Improvement}

The jitter of the complete current starved VCO is as shown in Figure 10. The Figure 11 shows the eye diagram of output waveforms of the VCO after divider.

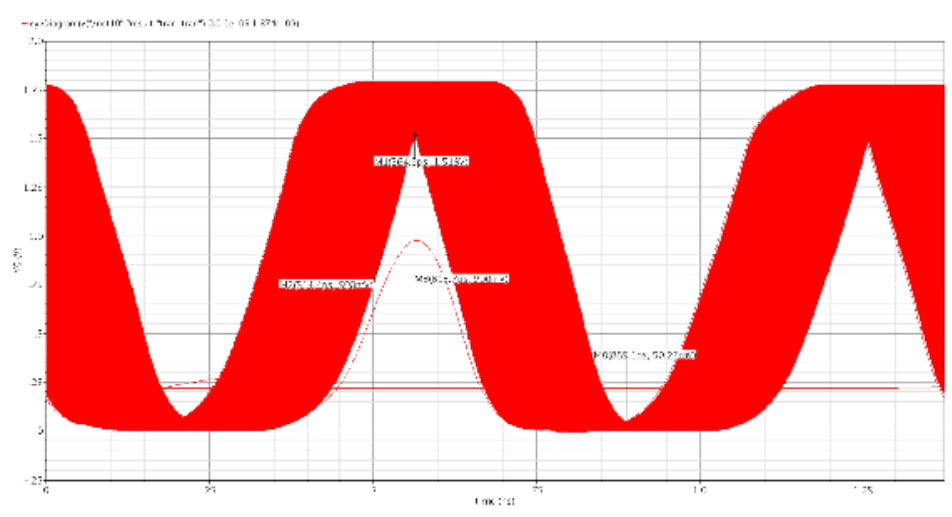

Figure 10. Eye diagram of the VCO output waveform at $1.456 \mathrm{GHz}$ when input is $1 \mathrm{~V}$ (Contains approx. 708 cycles).

There is a time difference of $99.3 \mathrm{ps}$ at $50 \%$ of $\mathrm{V}_{\mathrm{DD}}$. $\mathrm{V}_{\mathrm{DD}}$ values at top and bottom are $1.519 \mathrm{~V}$ and $50.22 \mathrm{mV}$ respectively. The time jitter can still be made less by connecting a D flip flop at output of VCO. But we get half of the VCO output frequency. In this design we observed the maximum time jitter after D flip flop 3.1ps and $1.5 \mathrm{ps}$ for rising and falling edge respectively, and output frequency is from $173 \mathrm{MHz}$ to $1.2 \mathrm{GHz}$.

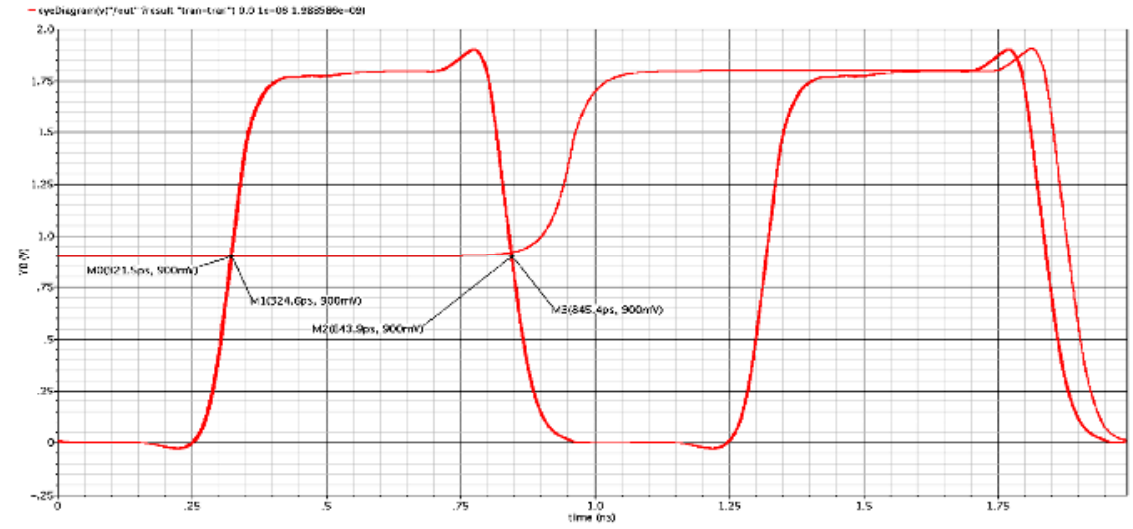

Figure 11. Jitter calculation after D Flip flop (Divide by 2).

\section{CONCLuSions}

The CSVCO circuit is designed and simulated using GPDK 180nm CMOS Technology. The CSVCO has frequency range from $53 \mathrm{MHz}$ to $2.348 \mathrm{GHz}$ and power consumption is $848 \mu \mathrm{W}$. The jitter is improved by connecting a D Flip Flop (divide by 2). The supply voltage $V_{D D}$ is $1.8 \mathrm{~V}$. The current starved oscillator gives a linear voltage controlled oscillations, which is useful for PLL upto a certain GHz frequency range. 
International Journal on Cybernetics \& Informatics ( IJCI) Vol.2, No.1, February 2013

\section{ACKNOWLEDGMENT}

The authors would like to acknowledge CEO of ekLakshya VLSI R\&D Centre, Hubli, Karnataka, India. We express our sincere thanks to Principal Prof. Dr. S. Mohan Kumar and Prof. Dr. Vijaya C., Head of the Department, staff of Department of E\&CE, SDM College of Engineering and Technology, Dharwad for providing their valuable assistance to carry out this work.

\section{REFERENCES}

[1] Floyd M Gardner, Phase Lock Techniques, 3rd ed., Wiley Interscience Publication, 2005.

[2] R. Jacob Baker. CMOS circuit design, Layout and simulation, John Wiley and Sons Inc, Publication, 2010.

[3] Paul R Gray, Paul J Hurst, Stephen H. Lewis, Robert G. Meyer, Analysis and Design of Analog Integrated Circuits, $4^{\text {th }}$ Edition, John Wiley \& Sons, Inc.

[4] Farid Golnaraghi, Benjamin C. Kuo, Automatic Control Systems, $9^{\text {th }}$ Edition, John Wiley \& Sons, Inc.

[5] Roland E. Best, Phase-Locked Loops Design, Simulation and Applications, $5^{\text {th }}$ edition, McGrawHill Publications.

[6] William F. Egan, Phase-Lock Basics, John Wiley \& Sons, Inc.

[7] Stanley Goldman, Phase-Locked Loop Engineering Handbook for Integrated Circuits, Artech House, Inc, 2007.

[8] Behzad Razavi, RF Microelectronics, Prentice Hall communication engineering series.

[9] Behzad Razavi, Design of Analog CMOS Integrated Circuits, International Edition, McGraw Hill publications, 2001.

[10] Cadence manual, 2004.

\section{Authors \\ Short Biography}

Mr. Madhusudan Kulkarni was born in Kukanur Karnataka in 1978. He received the AMIE Degree in Electronics and Communication Engineering from Institution of Engineers (India), Kolkata in 2005 \& pursuing M.Tech. Degree in Digital Electronics at SDMCET, Dhavalgiri, Dharwad. Currently he is working on Design of PLL for RF application. He was Head of Department and Lecturer in Electronics \& Communication at Oxford Polytechnic, Hubli. His interests are in Digital System Design using VLSI/CMOS Technology, Analog and Mixed mode Designs and Network Analysis.

Prof. Kalmeshwar N. Hosur was born in Karnataka in 1975. He received the M.Tech. in VLSI Design and Embedded Systems from VTU extension centre, SJCE Mysore in 2007. Currently he is working as Assistant Professor - Senior Grade, Department of Electronics and Communication, SDMCET, Dhavalgiri, Dharwad and he is pursuing Ph.D. at VTU, Belgaum. His interests of research are in VLSI Field (Data Converter Architectures, Analog Electronic Circuits, Network Analysis, CMOS VLSI Design, Analog \& Mixed Mode VLSI Circuits, VHDL).
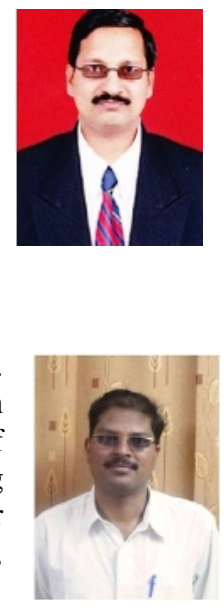